
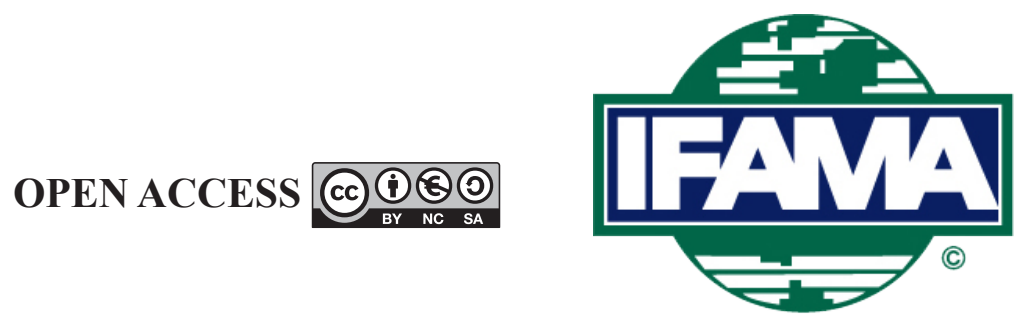

International Food and Agribusiness Management Review

Volume 24, Issue 5, 2021; DOI: 10.22434/IFAMR2020.0086

Received: 7 June 2020 / Accepted: 20 February 2021

\title{
Members of cooperatives: more heterogeneous, less satisfied?
}

\author{
RESEARCH ARTICLE \\ Jasper Grashuis ${ }^{\circledR \mathrm{a}}$ and Michael Lee Cook $^{\mathrm{b}}$ \\ ${ }^{a}$ Assistant Research Professor, ${ }^{b}$ Professor, University of Missouri, Division of \\ Applied Social Sciences, Mumford Hall, Columbia, MO 65211, USA
}

\begin{abstract}
The ability to successfully engage in collective action is often related to group heterogeneity. In the case of farmer cooperatives, member heterogeneity is often assumed to relate negatively to long-term performance. However, applied research is lacking in part because of the difficulty in measuring and matching farm-level and firm-level constructs. Using 1,061 survey responses from members of an organic food and beverage marketing cooperative, we develop a solution by measuring heterogeneity in age, education, farm experience, farm size, and membership length as the absolute difference from the median, which is interpreted as the base case with zero heterogeneity. A structural equation model is developed to relate our measurement of member heterogeneity to membership satisfaction. The latent factor of member heterogeneity is manifested significantly by each measure of individual heterogeneity (except age). Furthermore, as expected, member heterogeneity has a negative relationship to the latent factor of membership satisfaction. Our study demonstrates an ability to measure heterogeneity in continuous as opposed to binary form (e.g. small or large, young or old), and to explore the heterogeneity-performance relationship with farm-level observations.
\end{abstract}

Keywords: member heterogeneity, agricultural cooperative, producer organization, structural equation modeling, member satisfaction

JEL code: Q13, C38, D71

\footnotetext{
(i)Corresponding author: grashuisj@missouri.edu
} 


\section{Introduction}

The ability to successfully engage in collective action is often related to group heterogeneity (e.g. Gavrilets, 2015; Ostrom, 2010). Considering the general applicability of the various theories and frameworks of collective action and natural resource management (Hagedorn, 2013), the concept of group heterogeneity has also been studied in relation to farm producers who are organized to achieve some type of common goal (e.g. Barham and Chitemi, 2009; Dentoni et al., 2012; Markelova and Mwangi, 2010).

It is therefore no surprise to see group heterogeneity is also of considerable interest to farmer cooperatives (Höhler and Kühl, 2018), which are owned and controlled by organized farm producers to collectively market farm outputs or purchase farm inputs. In farmer cooperatives, members do not only wear a patron hat (i.e. suppliers or customers), but also an investor hat, an owner hat, and a community member hat (Limnios et $a l ., 2018)$. Each hat represents a different set of objectives or preferences, some of which are complementary and some of which are contradictory (Benos et al., 2018; Soboh et al., 2009). Member heterogeneity is hypothesized to lay at the very foundation of the degeneration of farmer cooperatives as diversity in attitudes and objectives may foster collective action problems and skew the balance between producing and consuming the collective good (Cook, 2018; Puusa et al., 2016).

The relationship of member heterogeneity to the firm-level performance of farmer cooperatives has been an explicit emphasis in the recent literature (Höhler and Kühl, 2018). For example, Iliopoulos and Valentinov (2017) conducted a case study of a farmer cooperative in Central Greece, using in-depth interviews with 11 informants to learn about the diversity in objectives or preferences. Much of the observed heterogeneity in size and production related to capital constraints in collective business opportunities, with producers of one commodity expressing reluctance to help finance resources for another commodity. Consequently, Iliopoulos and Valentinov (2017) concluded the farmer cooperative experienced a portfolio problem and struggled to develop a clear business strategy. In relation to a beef marketing cooperative in the United States, Hooks et al. (2017) observed heterogeneity in the member preferences for non-member beef purchases. While some members supported non-member beef purchases to secure enough supply for longterm access to retail markets, other members perceived an erosion of the cooperative values and principles and thus resisted the idea of further expansion by means of non-member beef purchases. Hooks et al. (2017) noted the heterogeneity may threaten the future position of the beef marketing cooperative in the value chain. With a case study of two large and heterogeneous Danish and German cooperatives, Höhler (2019) developed an extensive framework with numerous hypotheses to potentially explain why member heterogeneity is not necessarily related to exit behavior. According to the author, concepts from theories of collective action, fairness, and identity suggest the firm-level performance of farmer cooperatives is likely perceived differently by individuals who deviate from the stereotypical image of homo economicus. Hypothetically, such individuals have a greater tolerance for observed or perceived heterogeneity in payoffs and other measurements. Thus, by countering the findings of Iliopoulos and Valentinov (2017) and Hooks et al. (2017), Höhler (2019) suggested the heterogeneity-performance relationship is complex and multi-dimensional.

However, excepting case study research, the heterogeneity-performance relationship in farmer cooperatives has been subjected to few large-N empirical applications. To the best of our knowledge, the lone exception is by Elliott et al. (2018), who used aggregated survey data on farm operator characteristics to explain and predict state-level indicators of cooperative activity in the United States (i.e. total volume, total number of farmer cooperatives). Otherwise, the general lack of applied research is in part explained by the fact member heterogeneity is a farm-level construct, while cooperative performance is a firm-level construct. Furthermore, the very concept of cooperative firm performance is complex and ambiguous, often characterized by multiple objectives with competing parameters and constraints (Benos et al., 2018; Soboh et al., 2009). We seek to address the gap in the empirical literature by following the recommendations of Höhler and Kühl (2018), who identified the various dimensions of member heterogeneity in farmer cooperatives and posed questions to be addressed by future research endeavors. In response to Höhler and Kühl (2018), we use survey data 
collected by an organic food and beverage marketing cooperative in the United States to measure farm-level heterogeneity, which we subsequently use to inform farm-level satisfaction with firm-level membership (i.e. membership satisfaction).

We proceed as follows. In Section 2 we present a brief review of the literature on group heterogeneity in collective action as well as member heterogeneity in farmer cooperatives. We also discuss the empirical literature in which membership satisfaction is used as an outcome variable. Section 3 discusses the methodology, including our data sources, variable measurements, and model specifications. We present our results in Section 4, after which we conclude with a discussion of implications and recommendations for academics and practitioners in Section 5.

\section{Conceptual model}

\subsection{Member heterogeneity}

Group formation is often predicated on the existence of a single common objective (Olson, 1965). The group is formed if the expected benefit surpasses the startup cost of organization. However, following the formation, differences in individual objectives and preferences may become obvious and thus affect the production and consumption of the collective good. In game theory parlance, heterogeneity may alter the payoff structure of collective action and increase the benefit of defecting as opposed to cooperating.

In relation to farmer cooperatives, the concept of member heterogeneity has been discussed in the literature for a long time (e.g. Helmberger, 1966; Staatz, 1987). So far, most of the research on member heterogeneity in farmer cooperatives has been theoretical (Fulton and Giannakas, 2013) and conceptual (Cook, 2018), though applied research is also on the rise (Elliott et al., 2018; Höhler, 2019; Hooks et al., 2017; Iliopoulos and Valentinov, 2017). In most instances, member heterogeneity is discussed with a negative connotation. At the very least, member heterogeneity is acknowledged to add further complexity and ambiguity to the objective function of farmer cooperatives (Soboh et al., 2009).

Of course, individual objectives and preferences are often unobserved (i.e. latent constructs). Member heterogeneity is therefore often proxied by individual characteristics. For example, preferences for the distribution of costs and benefits may change according to age (e.g. older members may not want to invest equity for investment in long-term projects), farm size (e.g. larger members may want a proportional share of the control), education (e.g. college graduates may want to invest in research and development), product quality (e.g. high quality producers may want a separate pool with a price premium and pursue a collective strategy of differentiation), membership length (e.g. long-time members may want restrictive member access policies), and many other characteristics (Höhler and Kühl, 2018).

The topic of member heterogeneity is still of current interest because of the increasing size of farmer cooperatives. In the United States, there are increasingly few but large farmer cooperatives (U.S. Department of Agriculture, 2018), in part because of the recent increase in merger and acquisition activity (Grashuis and Elliott, 2018; Grashuis and Franken, 2020). The total number of farmer cooperatives in the United States has decreased from around 3,300 in the year 2000 to below 2,000 in the year 2020. The organizational growth of farmer cooperatives is associated with decreases in involvement and trust (Nilsson et al., 2009, 2012), and increases in the cost of making decisions and monitoring non-member decision specialists (Nilsson and Svendsen, 2011; Pozzobon and Zylbersztajn, 2013).

\subsection{Membership satisfaction}

Unlike public corporations, which stereotypically pursue profit maximization, farmer cooperatives do not conform to one specific objective (Benos et al., 2018; Soboh et al., 2009). As members are both patrons and investors, there exist inherent constraints to the ability of farmer cooperatives to maximize profit or 
minimize cost. Put differently, members are simultaneously buyers and sellers with competing objectives. Cooperative firm performance is therefore best indicated by both objective (i.e. financial) and subjective indicators (e.g. Benos et al., 2016; Franken and Cook, 2015).

A common subjective indicator of cooperative firm performance is membership satisfaction. Numerous researchers have used membership satisfaction as an outcome variable, usually with farm-level and memberlevel characteristics as predictors (e.g. Arcas-Lario et al., 2014; Grashuis and Cook, 2019; Hansen et al., 2002; Hernández-Espallardo et al., 2012; Morrow et al., 2004; Nilsson et al., 2009). Membership satisfaction is a strong predictor of long-term commitment (Arcas-Lario et al., 2014; Grashuis and Cook, 2019; HernándezEspallardo et al., 2012), which is essential to the future viability of farmer cooperatives. As the members are patrons as well as investors of farmer cooperatives, membership satisfaction is likely to be correlated with firm-level financial performance measurements such as price, turnover, and profit.

Our conceptual model is illustrated in Figure 1. Following the general hypotheses of Höhler and Kühl (2018) and Cook (2018), we assume member heterogeneity is related negatively to membership satisfaction.

\section{Methods}

\subsection{Data}

We use proprietary survey data collected by an organic food and beverage marketing cooperative with a membership of over 2,000 farm producers in the United States. Conducted during the spring season of 2017, the survey yielded a total of 1,402 responses. Because of missing information, we deleted 341 observations and proceeded with a sample size of 1,061. In Table 1, we report the summary statistics for certain farm-level and member-level characteristics. First, the sample is believed to be representative of the cooperative as well as the overall population of farm operators in the United States (U.S. Census of Agriculture). ${ }^{1}$ Second, in the far-right column we report the coefficient of variation, which is often used to indicate heterogeneity among panel subjects in the literature on collective action and natural resource management (e.g. Holl et al., 2013; McCarthy et al., 2004; Platteau and Seki, 2007). In our case, the coefficient of variation is indicative of relatively high within-sample heterogeneity in terms of farm size, both in terms of the number of acres and animals. For the other continuous variables (i.e. farm experience, organic farm experience, membership length), the coefficient of variation is below one. However, the coefficient of variation is only an overall

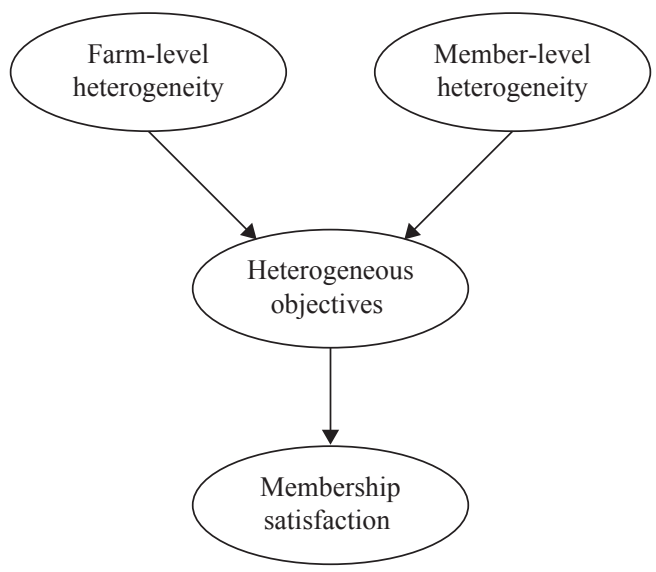

Figure 1. Conceptual model of the relationship of member heterogeneity to membership satisfaction.

\footnotetext{
${ }^{1}$ It is difficult to fully compare the sample to the overall population of U.S. farm operators as most of the farm-level and member-level characteristics are measured and reported differently in the U.S. Census of Agriculture (U.S. Department of Agriculture, 2019). Therefore, it is often impossible to calculate means and medians.
} 
Table 1. Summary statistics of survey respondent characteristics.

\begin{tabular}{lllll}
\hline Variable & Mean & SD $^{\mathbf{1}}$ & Median & Coefficient of variation \\
\hline Farm experience (years) & 21.35 & 14.09 & 19.00 & 0.66 \\
Organic farm experience (years) & 9.01 & 6.41 & 9.00 & 0.71 \\
Farm size (acres) & 276.17 & 327.72 & 176.00 & 1.19 \\
Farm size (animals) & 652.98 & $2,509.39$ & 95.00 & 3.84 \\
Age & & & & \\
24 or younger & 0.02 & 0.14 & 0.00 & 7.00 \\
25-34 & 0.17 & 0.38 & 0.00 & 2.24 \\
$35-44$ & 0.30 & 0.46 & 0.00 & 1.53 \\
45-54 & 0.23 & 0.42 & 0.00 & 1.83 \\
55-64 & 0.22 & 0.42 & 0.00 & 1.91 \\
$\quad 65+$ & 0.05 & 0.23 & 0.00 & 4.60 \\
Education & & & & \\
$8^{\text {th }}$ grade equivalent & 0.54 & 0.50 & 1.00 & 0.93 \\
Some high school & 0.02 & 0.13 & 0.00 & 6.50 \\
High school diploma & 0.17 & 0.38 & 0.00 & 2.24 \\
Technical degree & 0.07 & 0.25 & 0.00 & 3.57 \\
Some college & 0.08 & 0.27 & 0.00 & 3.38 \\
College degree & 0.10 & 0.30 & 0.00 & 3.00 \\
Advanced degree & 0.02 & 0.14 & 0.00 & 7.00 \\
Membership length (years) & 5.77 & 4.86 & 5.08 & 0.84 \\
\hline 1 SD = standard deviation. & & & &
\end{tabular}

${ }^{1} \mathrm{SD}=$ standard deviation.

indication of heterogeneity for each variable. It is therefore not possible to claim an absence of individual heterogeneity, even if the coefficient of variation is relatively low.

\subsection{Measurements of member heterogeneity and membership satisfaction}

Per the recommendations of Höhler and Kühl (2018), we use the following farm-level and member-level characteristics to proxy heterogeneity: age, education, farm experience, farm size, and membership length. These characteristics are among the most frequently used indicators of member heterogeneity in the literature on farmer cooperatives. Statistically, we measure heterogeneity as the absolute distance from the median, which in our case is a superior indicator of central tendency as compared to the mean. For most of the characteristics, the mean surpasses the median, which indicates the presence of influential observations in the right tail of the distribution. The mean is therefore biased toward such influential observations, which are not representative of the sample.

Thus, to measure heterogeneity, we first median-center each variable by subtracting the median from each value. The new median thus becomes zero. Second, we turn negative values into positive values so as to make the median (i.e. 0 ) the baseline scenario. Otherwise, the value 0 is not interpretable as 'zero heterogeneity' in relation to both positive and negative values. We therefore do not consider positive values and negative values as two different measurements of heterogeneity (i.e. -1 and 1 have the same interpretation). Thus, generally, the greater the distance from the median (i.e. 0), the greater the heterogeneity. While similar in interpretation to the coefficient of variation, our measurement of heterogeneity is applicable to each respondent as opposed to the whole sample. Table 2 reports the summary statistics for the median-centered farm-level and member-level measurements of heterogeneity, and Table 3 contains the correlation coefficients. 
Table 2. Summary statistics of the farm-level and member-level measurements of heterogeneity.

\begin{tabular}{llll}
\hline Variable & Mean & SD $^{\mathbf{1}}$ & Median \\
\hline Farm experience (years) & 11.33 & 9.02 & 10.00 \\
Organic farm experience (years) & 5.01 & 3.98 & 4.00 \\
Farm size (acres) & 171.65 & 302.35 & 80.00 \\
Farm size (animals) & 589.98 & $2,502.95$ & 36.00 \\
Age & 1.04 & 0.73 & 1.00 \\
Education & 1.49 & 1.88 & 0.00 \\
Membership length (years) & 3.84 & 3.09 & 3.50 \\
\hline
\end{tabular}

${ }^{1} \mathrm{SD}=$ standard deviation.

Table 3. Correlation matrix.

\begin{tabular}{llrrrrrr}
\hline & $\mathbf{1}$ & $\mathbf{2}$ & $\mathbf{3}$ & $\mathbf{4}$ & $\mathbf{5}$ & $\mathbf{6}$ & $\mathbf{7}$ \\
\hline 1. Farm experience & 1.00 & & & & & & \\
2. Organic farm experience & 0.17 & 1.00 & & & & & \\
3. Farm size (acres) & 0.23 & 0.10 & 1.00 & & & & \\
4. Farm size (animals) & 0.00 & 0.13 & 0.02 & 1.00 & & & \\
5. Age & 0.23 & 0.10 & -0.04 & 0.01 & 1.00 & & \\
6. Education & 0.31 & 0.12 & 0.33 & -0.07 & -0.05 & 1.00 & \\
7. Membership length & 0.17 & 0.40 & 0.10 & 0.03 & -0.07 & 0.18 & 1.00 \\
\hline
\end{tabular}

Like prior studies in the empirical literature on farmer cooperatives (Arcas-Lario et al., 2014; Grashuis and Cook, 2019; Hansen et al., 2002; Hernández-Espallardo et al., 2012; Morrow et al., 2004; Nilsson et al., 2009), we model membership satisfaction as a latent factor manifested by five five-point Likert statements, each of which is anchored by 'entirely disagree' and entirely agree' (Table 4). As indicated by Cronbach's alpha, the internal consistency of the latent factor is 0.78 . Furthermore, the Kaiser-Meyer-Olkin measure of sampling adequacy is 0.80 , suggesting we are justified to use the five Likert statements to model membership satisfaction as a latent factor comprising the five Likert statements.

\subsection{Method}

Considering the involvement of latent factors in our conceptual model, we use structural equation modeling (SEM) to explore the statistical relationships. SEM has a long history in the field of social sciences (Tarka, 2018), in particular in sociology and psychology. The method is also used increasingly often by economists who incorporate behavioral science. By combining the characteristics of exploratory or confirmatory factor analysis and multiple regression (Ullman, 2001), SEM involves the analysis of covariances and correlations to test causal assumptions (Bollen and Pearl, 2013). As the name suggests, SEM is used to simultaneously

Table 4. Summary statistics of the manifest variables for the latent factor membership satisfaction.

\begin{tabular}{llll}
\hline Likert statement & Mean & SD $^{\mathbf{1}}$ & Median \\
\hline 1. I am satisfied with my membership in the cooperative. & 4.20 & 0.76 & 4.00 \\
2. The cooperative pays fair prices. & 4.43 & 0.69 & 5.00 \\
3. I feel grateful to be a member of the cooperative. & 4.64 & 0.55 & 5.00 \\
4. I would recommend membership to another farmer. & 4.62 & 0.63 & 5.00 \\
5. I am satisfied with the quality of the communication. & 4.12 & 0.79 & 4.00 \\
\hline
\end{tabular}

${ }^{1} \mathrm{SD}=$ standard deviation. 
test causal relationships in: (1) the measurement model, which contains the relationships between the latent variables and its manifest variables; and (2) the structural model, which contains the relationships between the latent variables. While SEM has its share of critics, its appeal is based on the ability to construct hypothetical or latent constructs (e.g. aggression, happiness, power), simultaneously estimate a system of equations with multiple exogenous and endogenous variables, and measure both direct and indirect causal relationships (Kline, 2015; Tarka, 2018). Overall, SEM is a data analysis technique and process to help analyze phenomena with complex foundations and interrelationships, which is exactly why SEM has been used in the recent literature in relation to farmer cooperatives (e.g. Arcas-Lario et al., 2014; Castilla-Polo et al., 2017; Grashuis and Cook, 2019).

Using standard notation (Jöreskog, 1973), the structural model is defined as:

$$
\eta=B \eta+\Gamma \xi+\zeta
$$

where, if $q$ is the number of outcome variables and $r$ is the number of predictors, $\eta$ is the $q x l$ vector of endogenous latent variables (i.e. outcome variables), $\xi$ is the $r \times 1$ vector of exogenous latent variables (i.e. predictors), and $\zeta$ is the latent stochastic term. $B$ and $\Gamma$ are the $q x q$ and $q x r$ vectors of parameters for the endogenous and exogenous latent variables, respectively. There is one equation for each outcome variable in the structural model. The measurement model is defined as:

$$
y=\Lambda_{y} \eta+\varepsilon
$$

and

$$
x=\Lambda_{x} \xi+\delta
$$

where $x$ is the vector of manifest variables in relation to the exogenous latent variables, $y$ is the vector of manifest variables for the endogenous latent variables, $\Lambda$ is the vector of random parameters to be estimated, and $\delta$ and $\varepsilon$ are the stochastic terms for $x$ and $y$, respectively. Our full structural equation model is illustrated in Figure 2 and estimated in Stata 16 (StataCorp LLC, College Station, TX, USA).

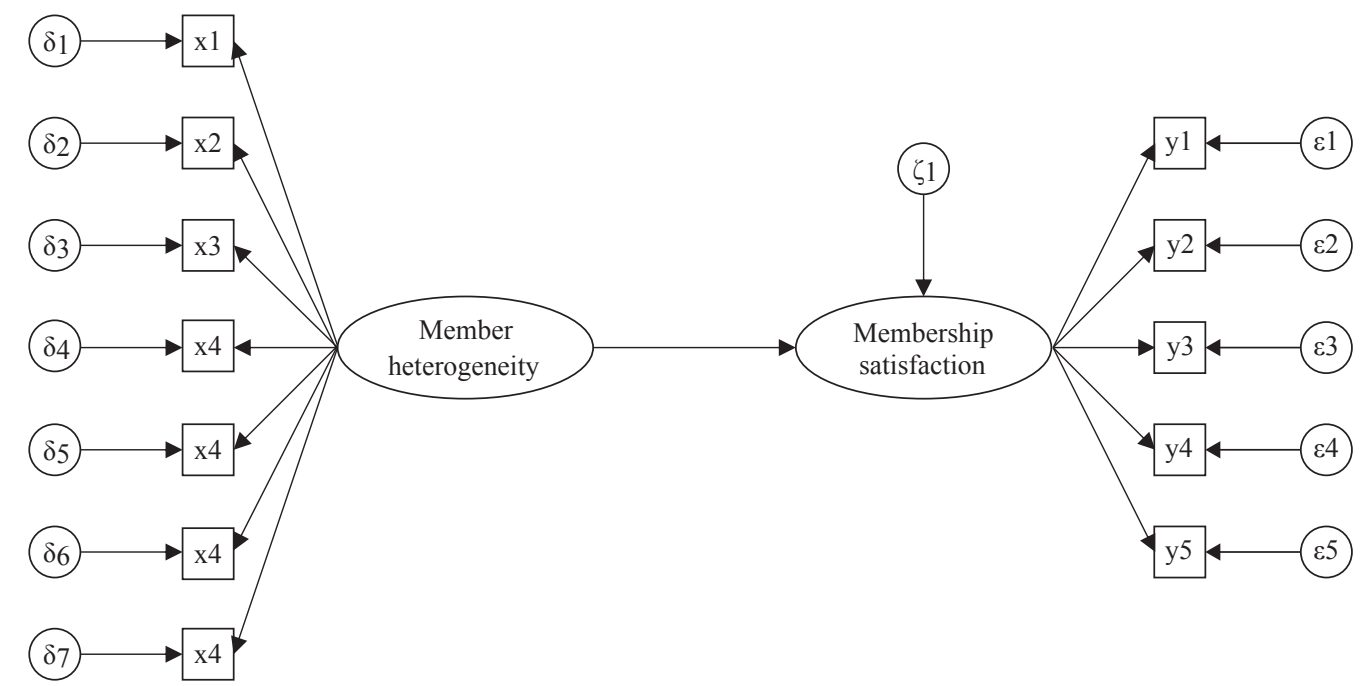

Figure 2. Structural equation model of member heterogeneity and membership satisfaction. 


\section{Results}

Typically, the first step in the SEM process is to conduct confirmatory factor analysis to estimate and evaluate the measurement model (i.e. the relationships of the latent variables to its manifest variables) (Kline, 2015). As reported in Table 5, common indices (comparative fit index $=0.81$, Tucker-Lewis index $=0.77$, root mean square error of approximation $=0.09$ ) do not indicate an acceptable fit between the measurement model and the observed data (Hooper et al., 2008; Kline, 2015; Schreiber et al., 2006). The problem is in large part attributable to the standardized path loading from the latent factor Member Heterogeneity to the age variable, which is not characterized by statistical significance. The result implies heterogeneity in terms of age is not related significantly to the latent factor Member Heterogeneity as manifested by the other farmlevel and member-level characteristics.

The nonsignificant relationship of age to the latent factor Member Heterogeneity is arguably an indication of the lack of horizon problems in our subject. The horizon problem, which relates to the disincentives for relatively old members to invest or retain equity at the firm-level, is hypothesized to contribute to degeneration in farmer cooperatives (Cook, 2018). While our finding is in favor of arguments by Bogetoft and Olesen (2007), who challenged the existence of horizon problems in farmer cooperatives, the result is perhaps attributable to the complex yet innovative equity structure of our subject. Their equity structure has multiple common and preferred stock classes, which enables the balancing of investment preferences and the transferring of active and inactive capital suppliers. An alternative explanation is provided by Franken and Cook (2019), who produced evidence in favor of three different types of horizon problems. Our secondary data lack the necessary sophistication to address the relationship of age to multiple dimensions of member behavior.

Table 5. Results of the measurement model (original and final).

\begin{tabular}{|c|c|c|c|c|c|}
\hline & & Original $\mathbf{m}$ & & Final mod & \\
\hline Manifest variable & Latent factor & $\beta$ & $P>|\mathbf{z}|$ & $\boldsymbol{\beta}$ & $P>|z|$ \\
\hline Likert statement 1 & \multirow[t]{5}{*}{ membership satisfaction } & 0.757 & 0.000 & 0.753 & 0.000 \\
\hline Likert statement 2 & & 0.635 & 0.000 & 0.635 & 0.000 \\
\hline Likert statement 3 & & 0.632 & 0.000 & 0.633 & 0.000 \\
\hline Likert statement 4 & & 0.682 & 0.000 & 0.680 & 0.000 \\
\hline Likert statement 5 & & 0.557 & 0.000 & 0.557 & 0.000 \\
\hline Farm experience & \multirow[t]{7}{*}{ member heterogeneity } & 0.480 & 0.000 & 0.560 & 0.000 \\
\hline Organic farm experience & & 0.287 & 0.000 & 0.220 & 0.000 \\
\hline Farm size (acres) & & 0.575 & 0.000 & 0.426 & 0.000 \\
\hline Farm size (animals) & & 0.268 & 0.000 & 0.194 & 0.000 \\
\hline Age & & 0.030 & 0.461 & & \\
\hline Education & & 0.623 & 0.000 & 0.558 & 0.000 \\
\hline Membership length & & 0.330 & 0.000 & 0.305 & 0.000 \\
\hline \multicolumn{6}{|l|}{ Goodness-of-fit } \\
\hline RMSEA $^{1}$ & & 0.09 & & 0.06 & \\
\hline $\mathrm{CFI}^{1}$ & & 0.81 & & 0.94 & \\
\hline $\mathrm{TLI}^{1}$ & & 0.77 & & 0.91 & \\
\hline $\mathrm{AIC}^{1}$ & & $41,101.59$ & & $38,691.16$ & \\
\hline $\mathrm{BIC}^{1}$ & & $41,285.26$ & & $38,884.87$ & \\
\hline
\end{tabular}


In addition to accounting for the covariances among the manifest variables, the removal of the age variable improves the overall goodness-of-fit considerably in the revised measurement model (comparative fit index $=0.94$, Tucker-Lewis index $=0.91$, root mean square error of approximation $=0.06$ ). We can also judge the measurement model by the practical and statistical significance of all the standardized path loadings. For example, an increase of one standard deviation in farm experience ( 9.02 years) facilitates an increase of 0.56 standard deviations in the latent factor Member Heterogeneity, ceteris paribus. As a reminder, each variable measures the absolute deviation from the median, which implies the estimate applies to both positive and negative differences. Also, all the standardized path loadings are positive, suggesting an increase in each of the farm-level and member-level measurements of heterogeneity has the same type of relationship to the latent factor member heterogeneity.

The next step is to estimate and evaluate the full structural model, which concerns the hypothesized relationship of member heterogeneity to membership satisfaction. We report the results in Table 6 . The final model conforms to the goodness-of-fit criteria (comparative fit index $=0.98$, Tucker-Lewis index $=0.97$, root mean square error of approximation $=0.03$ ) set in the literature (Hooper et al., 2008; Kline, 2015; Schreiber et al., 2006). Corresponding to our research question, we observe a significant standardized path loading from member heterogeneity to membership satisfaction, which corresponds to our general hypothesis of member heterogeneity having a negative relationship to membership satisfaction (Höhler and Kühl, 2018). The direct effect is estimated at -0.151 . Using mediation, each of the farm-level and member-level measurements of

Table 6. Results of the structural model.

\begin{tabular}{|c|c|c|c|c|}
\hline Manifest variable & Latent factor & Direct effect & Indirect effect & $P>|z|$ \\
\hline Likert statement 1 & membership satisfaction & 0.763 & & 0.000 \\
\hline Likert statement 2 & membership satisfaction & 0.592 & & 0.000 \\
\hline Likert statement 3 & membership satisfaction & 0.645 & & 0.000 \\
\hline Likert statement 4 & membership satisfaction & 0.693 & & 0.000 \\
\hline Likert statement 5 & membership satisfaction & 0.503 & & 0.000 \\
\hline \multirow[t]{2}{*}{ Farm experience } & member heterogeneity & 0.551 & & 0.000 \\
\hline & membership satisfaction & & -0.083 & 0.002 \\
\hline \multirow[t]{2}{*}{ Organic farm experience } & member heterogeneity & 0.254 & & 0.000 \\
\hline & membership satisfaction & & -0.038 & 0.007 \\
\hline \multirow[t]{2}{*}{ Farm size (acres) } & member heterogeneity & 0.416 & & 0.000 \\
\hline & membership satisfaction & & -0.063 & 0.004 \\
\hline \multirow[t]{2}{*}{ Farm size (animals) } & member heterogeneity & 0.203 & & 0.000 \\
\hline & membership satisfaction & & -0.031 & 0.011 \\
\hline \multirow[t]{2}{*}{ Education } & member heterogeneity & 0.562 & & 0.000 \\
\hline & membership satisfaction & & -0.085 & 0.003 \\
\hline \multirow{2}{*}{ Membership length } & member heterogeneity & 0.315 & & 0.000 \\
\hline & membership satisfaction & & -0.047 & 0.004 \\
\hline Member heterogeneity & membership satisfaction & -0.151 & & 0.002 \\
\hline $\mathrm{n}$ & & $1,061.00$ & & \\
\hline Chi-square & & 76.62 & & \\
\hline RMSEA $^{1}$ & & 0.03 & & \\
\hline $\mathrm{CFI}^{1}$ & & 0.98 & & \\
\hline $\mathrm{TLI}^{1}$ & & 0.97 & & \\
\hline $\mathrm{AIC}^{1}$ & & $38,607.25$ & & \\
\hline $\mathrm{BIC}^{1}$ & & $38,810.89$ & & \\
\hline
\end{tabular}


heterogeneity also imposes an indirect effect on membership satisfaction via member heterogeneity. The standardized path loadings for all of the variables are statistically significant at the $95 \%$ confidence level.

Our main result corroborates the work of Hooks et al. (2017) and Iliopoulos and Valentinov (2017), who conducted case studies of farmer cooperatives in the United States and Greece, respectively, to illustrate the negative relationship of member heterogeneity to cooperative firm performance. We do not find support in the work of Elliott et al. (2018), which is the only other large-N empirical application in terms of the heterogeneityperformance relationship in farmer cooperatives. The contrast in our conclusions is likely attributable to vast differences in conceptualizations and measurements of both heterogeneity and performance. When extending the scope to the field of agribusiness, our result is similar to Dentoni et al. (2012), who studied Italian hog producers who participate in the Prosciutto di Parma network and found a negative relationship of heterogeneity to the willingness to invest in future cooperation. In the fields of collective action and natural resource management, group heterogeneity is often found to have no significant relationship to the robustness of common property institutions (e.g. Adhikari and Lovett, 2006; Gautam, 2007; Poteete and Ostrom, 2004). However, it is often explained by the presence of certain firm-level mechanisms or selective incentives which ameliorate the negative impact of group heterogeneity. For farmer cooperatives, common examples of such firm-level mechanisms or selective incentives are closed membership access policies, quality standards, and proportional voting structures (Cook, 2018; Cook and Iliopoulos, 2016). It is unclear if such generic and specific solutions can address heterogeneity in terms of every farm-level and member-level characteristic.

\section{Conclusions}

To the best of our knowledge, we are the first to explicitly measure member heterogeneity at the farm-level in continuous form. In prior studies with member-level data, member heterogeneity is often indicated by binary variables such as young/old, small/large, or low-quality/high-quality, but such approaches may not capture the full degree of heterogeneity. Further heterogeneity may exist within segments or categories which is obscured by binary measurements. Also, when using binary measurements of farm-level or member-level characteristics such as age or production size, there is no implication of heterogeneity unless the relationship to some outcome variable is estimated at different percentiles, not just the mean.

In our study, we provide a solution by using median-centered variables and interpreting the absolute difference from the median as the degree of heterogeneity. Using SEM, the overall statistical significance of the measurement model, as well as the structural model, indicates the median is the correct baseline to inform heterogeneity. In the context of our sample, which is considered to be representative of the U.S. population of farm operators in terms of key demographic characteristics, the median serves as the reference point for the other observations. However, it is very possible other types of measurements may better inform heterogeneity in other samples. The decision to use the mean, the median, or some other value to center variables is dependent on the distribution of the data. To be sure, in case of non-normal distributions, the median is likely to be a better measure of central tendency as compared to the mean.

Our novel study may inspire future research endeavors, in part by addressing some of its weaknesses and limitations. Our methodological approach to measuring heterogeneity only allowed the inclusion of continuous (i.e. farm experience, farm size, membership length) and ordinal variables (i.e. age, education). By design, we excluded binary variables such as gender or religion. With binary variables, the mean and the median are not good measures of central tendency. Yet many binary variables may significantly manifest member heterogeneity. How can binary variables inform overall heterogeneity from a statistical perspective, particularly in combination with continuous and ordinal variables? Also, our structural equation model is based on farm-level and member-level characteristics. While we find a negative relationship of member heterogeneity to membership satisfaction, there is not yet any empirical evidence of an observable effect at the firm-level. However, considering the positive relationship of membership satisfaction to long-term commitment, it is paramount to measure farm-level and member-level characteristics in addition to firmlevel indicators. Knowledge of data distributions will help identify heterogeneity within the membership, 
which stresses the importance of facilitating opportunities for members to share opinions and experiences in surveys or other communications. Finally, our empirical specification of member heterogeneity suffered from the use of secondary data. In the future, it is necessary to consider more indicators of member heterogeneity, such as farm-level objectives, farm succession plans, farm-level cost functions, farm locations, and farm product and service portfolios.

\section{References}

Adhikari, B. and J.C. Lovett. 2006. Institutions and collective action: does heterogeneity matter in communitybased resource management? The Journal of Development Studies 42(3): 426-445.

Arcas-Lario, N., J.F. Martín-Ugedo and A. Mínguez-Vera. 2014. Farmers' satisfaction with fresh fruit and vegetable marketing Spanish cooperatives: an explanation from agency theory. International Food and Agribusiness Management Review 17: 127-146.

Barham, J. and C. Chitemi. 2009. Collective action initiatives to improve marketing performance: lessons from farmer groups in Tanzania. Food Policy 34(1): 53-59.

Benos, T., N. Kalogeras, F.J. Verhees, P. Sergaki, P. and J. Pennings. 2016. Cooperatives' organizational restructuring, strategic attributes, and performance: the case of agribusiness cooperatives in Greece. Agribusiness 32(1): 127-150.

Benos, T., N. Kalogeras, M. Wetzels, K. Ruyter and J. Pennings. 2018. Harnessing a 'currency matrix' for performance measurement in cooperatives: a multi-phased study. Sustainability 10(12): 4536.

Bogetoft, P. and H. Olesen. 2007. Sales distortion in heterogeneous cooperatives. In: K. Karantininis and J. Nilsson (eds.) Vertical markets and cooperative hierarchies. Springer, Dordrecht, the Netherlands, pp. 213-223.

Bollen, K.A. and J. Pearl. 2013. Eight myths about causality and structural equation models. In: S.L. Morgan (ed.) Handbook of causal analysis for social research. Springer, Dordrecht, the Netherlands, pp. 301-328.

Castilla-Polo, F., M. Sánchez-Hernández and D. Gallardo-Vázquez. 2017. Assessing the influence of social responsibility on reputation: an empirical case study in agricultural cooperatives in Spain. Journal of Agricultural and Environmental Ethics 30(1): 99-120.

Cook, M.L. 2018. A life cycle explanation of cooperative longevity. Sustainability 10(5): 1586.

Cook, M.L. and C. Iliopoulos. 2016. Generic solutions to coordination and organizational costs: informing cooperative longevity. Journal on Chain and Network Science 16(1): 19-27.

Dentoni, D., D. Menozzi, D. and M. Capelli. 2012. Group heterogeneity and cooperation on the geographical indication regulation: the case of the 'Prosciutto di Parma' Consortium. Food Policy 37(3): 207-216.

Elliott, M., L. Elliott and E. Sluis. 2018. A predictive analytics understanding of cooperative membership heterogeneity and sustainability. Sustainability 10(6): 2048.

Franken, J.R. and M.L. Cook. 2015. Informing measurement of cooperative performance. In: J. Windsperger, G. Cliquet, Th. Ehrmann and G. Hendrikse (eds.) Interfirm networks. Springer International Publishing, Heidelberg, Germany, pp. 209-226.

Franken, J.R. and M.L. Cook. 2019. Horizon and portfolio investment constraints in agricultural cooperatives. In: Windsperger, G. Cliquet, G. Hendrikse and M. Srećković (eds.) Design and management of interfirm networks. Springer International Publishing, Heidelberg, Germany, pp. 179-196.

Fulton, M. and K. Giannakas. 2013. The future of agricultural cooperatives. Annual Review of Resource Economics 5(1): 61-91.

Gautam, A.P. 2007. Group size, heterogeneity and collective action outcomes: evidence from community forestry in Nepal. International Journal of Sustainable Development \& World Ecology 14 (6): 574-583.

Gavrilets, S. 2015. Collective action problem in heterogeneous groups. Philosophical Transactions of the Royal Society B: Biological Sciences 370 (1683): 20150016.

Grashuis, J. and J. Franken. 2020. Exit strategies of farmer co-operatives in the United States: a competing risks analysis. Journal of Co-operative Organization and Management 8(2): 100119. 
Grashuis, J. and M. Elliott. 2018. The role of capital capacity, spatial competition, and strategic orientation to mergers and acquisitions by US farmer cooperatives. Journal of Co-operative Organization and Management 6(2): 78-85.

Grashuis, J. and M.L. Cook. 2019. A structural equation model of cooperative member satisfaction and long-term commitment. International Food and Agribusiness Management Review 22(2): 247-263.

Hagedorn, K. 2013. Natural resource management: the role of cooperative institutions and governance. Journal of Entrepreneurial and Organizational Diversity 2(1): 101-121.

Hansen, M.H., J. Morrow Jr. and J. Batista. 2002. The impact of trust on cooperative membership retention, performance, and satisfaction: an exploratory study. The International Food and Agribusiness Management Review 5(1): 41-59.

Helmberger, P. 1966. Future roles for agricultural cooperatives. Journal of Farm Economics 48(5): 1427-1435.

Hernández-Espallardo, M., N. Arcas-Lario, N. and G. Marcos-Matás. 2012. Farmers'satisfaction and intention to continue membership in agricultural marketing co-operatives: neoclassical versus transaction cost considerations. European Review of Agricultural Economics 40(2): 239-260.

Höhler, J. 2019. Member heterogeneity and exit. In: G. Hendrikse, Windsperger, G. Cliquet and M. Srećković (eds.) Design and management of interfirm networks. Springer International Publishing, Heidelberg, Germany, pp. 197-216.

Höhler, J. and R. Kühl. 2018. Dimensions of member heterogeneity in cooperatives and their impact on organization - a literature review. Annals of Public and Cooperative Economics 89(4): 697-712.

Holl, K D., V. Stout, J. Reid and R. Zahawi. 2013. Testing heterogeneity-diversity relationships in tropical forest restoration. Oecologia 173(2): 569-578.

Hooks, T., O. McCarthy, C. Power and A. Macken-Walsh. 2017. A co-operative business approach in a values-based supply chain: a case study of a beef co-operative. Journal of Co-operative Organisation and Management 5(2): 65-72.

Hooper, D., J. Coughlan and M. Mullen. 2008. Structural equation modelling: guidelines for determining model fit. Electronic Journal of Business Research Methods 6(1): 53-60.

Iliopoulos, C. and V. Valentinov. 2017. Member preference heterogeneity and system-lifeworld dichotomy in cooperatives: an exploratory case study. Journal of Organisational Change Management 30(7): 1063-1080.

Jöreskog, K.G. 1973. A general method for estimating a linear structural equation system. In: A.S. Goldberger and O.D. Duncan (eds.) Structural equation models in the social sciences. Academic Press, New York, NY, USA.

Kline, R.B. 2015. Principles and practice of structural equation modeling, $4^{\text {th }}$ edition. Guilford Press, New York, NY, USA.

Limnios, E.M., T. Mazzarol, G. Soutar and K. Siddique. 2018. The member wears four hats: a member identification framework for co-operative enterprises. Journal of Co-operative Organization and Management 6(1): 20-33.

Markelova, H. and E. Mwangi. 2010. Collective action for smallholder market access: evidence and implications for Africa. Review of Policy Research 27(5): 621-640.

McCarthy, N., C. Dutilly-Diane and B. Drabo. 2004. Cooperation, collective action and natural resources management in Burkina Faso. Agricultural Systems 82(3): 233-255.

Morrow Jr, J., M. Hansen and A. Pearson. 2004. The cognitive and affective antecedents of general trust within cooperative organizations. Journal of Managerial Issues 16(1): 48-64.

Nilsson, J. and G. Svendsen. 2011. Free riding or trust? Why members (do not) monitor their cooperatives. Journal of Rural Cooperation 39: 131-150.

Nilsson, J., A. Kihlén and L. Norell. 2009. Are traditional cooperatives an endangered species? About shrinking satisfaction, involvement and trust. International Food and Agribusiness Management Review 12: 1-22.

Nilsson, J., G. Svendsen and G. Svendsen. 2012. Are large and complex agricultural cooperatives losing their social capital? Agribusiness 28(2): 187-204.

Olson, M. 1965. The logic of collective action: public goods and the theory of groups. Harvard University Press, Cambridge, MA, USA. 
Ostrom, E. 2010. Analyzing collective action. Agricultural Economics 41: 155-166.

Platteau, J.P. and E. Seki. 2007. Heterogeneity, social esteem and feasibility of collective action. Journal of Development Economics 83(2): 302-325.

Poteete, A.R., E. Ostrom. 2004. Heterogeneity, group size and collective action: the role of institutions in forest management. Development and Change 35(3): 435-461.

Pozzobon, D.M. and D. Zylbersztajn. 2013. Democratic costs in member-controlled organizations. Agribusiness 29(1): 112-132.

Puusa, A., K. Hokkila, A. Varis. 2016. Individuality vs. communality: a new dual role of co-operatives?. Journal of Co-operative Organisation and Management 4(1): 22-30.

Schreiber, J.B., A. Nora, F. Stage, E. Barlow and J. King. 2006. Reporting structural equation modeling and confirmatory factor analysis results: a review. The Journal of Educational Research 99(6): 323-338.

Soboh, R., A. Oude Lansink, G. Giesen and G. Van Dijk. 2009. Performance measurement of the agricultural marketing cooperatives: the gap between theory and practice. Review of Agricultural Economics 31(3): 446-469.

Staatz, J.M. 1987. The structural characteristics of farmer cooperatives and their behavioral consequences. Cooperative Theory: New Approaches 18: 33-60.

Tarka, P. 2018. An overview of structural equation modeling: its beginnings, historical development, usefulness and controversies in the social sciences. Quality \& Quantity 52(1): 313-354.

Ullman, J.B. 2001. Structural equation modeling. In: B.G. Tabachnick, and L.S. Fidell (eds.) Using multivariate statistics. Pearson Education, Boston, MA, USA.

U.S. Department of Agriculture. 2018. Cooperative statistics 2017. Rural Development Service Report 81. U.S. Department of Agriculture, Washington, DC, USA.

U.S. Department of Agriculture. 2019. 2017 Census of agriculture. U.S. Department of Agriculture, Washington, DC, USA. Available at: https://www.nass.usda.gov/Publications/AgCensus/2017/index.php 
